\section{Species selection: its range and power}

SIR-Loquacious and contentious primates that we are, too much of human debate concerns words rather than things. Yet terms and concepts must be clarified if we hope to gain any proper understanding of phenomena. Species selection is an important and confusing concept lying at the heart of attempts to reformulate evolutionary theory as a hierarchy of interacting levels ${ }^{i}$, rather than (as darwinian convention holds) a nearly exclusive proposition involving struggle among organisms for differential reproductive success.

Maynard Smith ${ }^{5}$ accused us of overextending the potential role of species selection by proposing it as a source for the origin of complex morphological adaptions. We agreed" that species selection could not work in such a manner, and pointed out that all proponents of the idea had always so acknowledged. (This conclusion is a simple statement of probability. Complex morphological adaptions, requiring the sequential accumulation and integration of hundreds of parts, cannot arise as the fortuitous side-consequence of a causal process acting at some other level - gene or species, for example. Such complexity must be causally built by selection working directly on the phenotypes of organisms.) Maynard $\mathrm{Smith}^{7}$ responded by citing quotations supposedly indicating our previous belief in species selection as a cause of complex morphological adaptations, and welcomed us back to sensible orthodoxy.

Changing one's mind is among the world's most salutary blessings, and a badge of valour and virtue - so we would be happy to acknowledge Maynard Smith's interpretation, if it were true. But we have not changed our position on species selection; we, and all palaeontologists involved in formulating this concept, have always recognized that it cannot explain complex morphological adaptations.

Maynard Smith's quotations simply illustrate a misunderstanding in the use of terms. The quotations all advocate species selection as a cause of palaeontological 'trends' and Maynard Smith has equated trends with complex adaptations. Not so. In our original paper on punctuated equilibrium $^{*}$ we defined trends as "biostratigraphic character gradients" the standard palaeontological usage. Most empirical trends in fossils are chronological gradients in simple characters, the most famous examples being trends towards increased body size expressed as Cope's rule". Indeed, it is the chief frustration of the fossil record that we do not have empirical evidence for sustained trends in the evolution of most complex morphological adaptations - the jaws and eyes of vertebrates, to cite two classic cases. Thus, palaeontological trends, properly defined, are the very aspects of morphology that are most subject to potential explanation by species selection, because trends are simple, sustained changes that can arise by hitchhiking on a process of sorting among species.

The acknowledgement that species selection cannot produce complex morphological adaptations is no vitation of its power or importance in evolution, but only a mark of avoiding a "category error' in understanding its action. Forces are appropriate to their levels; gravity is not unimportant in the Universe as a whole because quarks hardly notice it. Similarly, much of the genome, including 'selfish' DNA and 'outlaw' chromosomes, probably arises by gene-level selection, whereas the great patterns of differential diversity and its geological fluctuations are strongly impacted by species selection (can we really hope to explain why the world holds more than a million species of insects and only a dozen or so of priapulids by relative adaptive success of their equally complex morphologies alone?). But hierarchy theory is also fascinating because levels interact, and phenomena generated at one level have important effects at others. Thus, duplicated genes may be a prerequisite for flexibility in the evolution of morphological complexity, but they probably arise by genomic selection. And simple, sustained chronological gradients in morphology - the classical 'trends' of palaeontology - may be produced as effects of downward causation from species selection.

Maynard Smith ${ }^{7}$ ends by welcoming us back to his conceptual edifice. But while he was out crusading for his castle, the building was growing. The darwinian ground floor is as vibrant as ever, but a wonderful basement has been added for gene and cell-lineage level selection ${ }^{10}$ and a lovely attic for the level of species. The view from the top is puzzling, but endlessly fascinating.

STEPhen Jay Gould

Museum of Comparative Zoology,

Harvard University,

Cambridge, Massachusetts 02138, USA

Niles Eldredge American Museum of Natural History, New York, New York 10024, USA

1. Stanley, S. M. Proc. natn. Acad. Sci. U.S.A. 72, 646 (1975)

Gould, S. J. Science 216, 380-387 (1982)

Eldredge, N. Unfinished Symhesis (Oxford University Press. New York. 1985)

Vrba, E. S. \& Gould, S. J. Puleobiology 12, 217 (1986) Maynard Smith. J. Nature 330, 516 (1987)

Eldredge, N. \& Gould. S. J. Nature 332, 211-212 (1988) Maynard Smith. J. Nature 332, 312 (1988)

Iddredge, N. \& Gould, S. J. in Models in Puleobiology (ed Schopf. T. J. M.) 82-115 (Freeman Cooper. San Francisco, 1972).

Stanley, S. M. Evolution 27, 1-26 (1973)

10. Buss, L. The Evolution of Individuality (Princeton University Press, Princeton. NJ, 1987)

\section{Examples, please}

Sin-The most appropriate usage of the word 'homology' has been a continuing topic in the literature. One argument against restricting it to its precise, historical, biological meaning of common ancestry is that, in molecular biology, if it's similar it's homologous because you can't get molecular similarity on the basis of convergent evolution. I believe the persuasiveness of that argument depends largely on the lack of awareness of the (possible) occurrence of analogy at the molecular sequence level, and would like to collect examples. Accordingly, I would be grateful if readers could send me any instances they know of in which similarity is not the result of common ancestry.

Walter M. Fitch

Department of Biological Sciences,

University of Southern California,

Los Angeles.

California 90089-1340, USA

\section{Neither waves, nor particles, but quantons}

SIR-In discussing ${ }^{1}$ the continuing debate on the foundations of quantum theory and, more specifically, the physical nature of quantum entities, John Maddox summarizes the question by opposing "Bohr's opinion, now called the Copenhagen view, . . . that such an entity is . . either a wave, or a particle" with "the contrary view, due to De Broglie, ... that a quantum entity is both a wave and a particle". One might argue that Bohr's ideas were more subtle (and rather more obscure), but the description no doubt fits the widespread quantum vulgate, contrasting the two views - and only these two.

It is not surprising that the brave explorers who first landed on the quantum continent, more than 60 years ago, stumbling on its rather weird inhabitants, tried to describe them by reference to more familiar company. To classical or postclassical physicists there were only two types of physical entities, namely particles and waves. Since the strange quantum beings showed a behaviour reminiscent sometimes of particles and sometimes of waves, it was not unnatural to discuss them in classical terminology, under the philosophical cover of the ad hoc 'waveparticle duality'.

The conquistadors, discovering in the Andes a woolly and lipped animal looking somewhat like a sheep and somewhat like a camel, did not for long resort to camelsheep duality and soon used a native word, lama, to describe it. Nor did the gold-diggers of Australia keep to a duckrabbit duality for describing the furry duck-billed platypus. Despite partial simılarities, it was soon clear that these were 